\title{
EXPLORING GAIT, BALANCE PERFORMANCE AND FEAR OF FALLING AMONG ELDERLY PEOPLE LIVING IN RURALAREAS OF THAILAND
}

\author{
Pummarak S ${ }^{1}$, Samrongtong $\mathbf{R}^{1}$ and Ramesh Kumar ${ }^{2}$
}

${ }^{1}$ College of Public Health Sciences, Chulalongkorn University

${ }^{2}$ Health Services Academy Islamabad Pakistan.

Correspondence: sratana3@chula.ac.th

\begin{abstract}
Background: Previous evidence indicates that older people allocate more of their attentional resources toward their gait and that the attention-related changes that occur during aging increase the risk of falls.

Methods: A cross sectional study was conducted in Banna District and Ongkarak District, Nakornnayok Province, Thailand. One hundred elderly people participated in this study. Gait was assessed by a Time Up and Go Test (TUGT) while the One legged stance test (OLST) assessed balance performance. The Falls Efficacy Scale (FES) measured fear of falling of the elderly people. AWHOQOL-BREF instrument assessed the quality of Life among elderly people.

Results: The findings revealed that $58 \%$ of the participants were female, aged between $60-74$ years ( $m e a n=66.39$, SD 3.65). Over a 12 month period, $57 \%$ of participants had experienced a fall once, $41 \%$ had experienced 2 falls while $2 \%$ had experienced 3 or more falls. One-third of the elderly people who participated in the study had a fear of falling. Almost all of the elderly participants $(76 \%)$ had a moderate fall risk perception score. The mean score of total quality of life was moderate (80.43).

Conclusion: Study concluded that the elderly people face a valid risk of falling based on prevalent risk factors that results in a fear of falling. An assessment of fall risk factors are important in establishing a fall prevention program for the elderly faced with fall risk factor from fear of falling and. Assessment fall risk factors are important to provide the suitable falls prevention program for the elderly.
\end{abstract}

Keywords: Gait and balance, fall risk perception, fear of falling and elderly population

\section{Introduction}

Aging is often associated with changes in many functions such as visual problems, muscular degeneration, sensory problems, impaired gait and balance, reduced lower limb use and other conditions that would suggest an impact on risk of falling (1.2). Falls can cause serious consequences in the elderly, comprising injury, disability, loss of confidence, functioning problems, and mortality (3). Globally, the fall rate is rising rapidly and continuously in persons aged 60 years and over. The death rate, resulting from falls in 2002 was 39,100 and 424,000 in 2012 (4). In Thailand, falls were amongst the top 2 causes of unintentional injuries alongside traffic accidents. Unfortunately, fall related death rates average at 3/day, with male fall rates 3 times higher than female (5).

Falls in older people are caused by a variety of risk factors related to the ageing process, but are also influenced by a person's behavior, habits and environment (6). Problems with balance and mobility are the greatest risk factors for falls (7). With age and the ageing process, there is an increase in problems with balance and the risk of balance related falls because balance control is the foundation of human ability to move and function independently. Moreover, impaired gait and balance leads to tripping and slipping and loss of balance and balance impairment with aging and may cause mobility limitations and functional decline (8). Some studies have shown that individuals with balance impairment and mobility impairment were more likely to fall (9). Fear of falling is a psychological concern of the elderly people who have had previous experience of falling. Fear of falling leads to avoiding some activities and sometimes individuals limit their activities in order to improve their safety. This is important because it can limit physical and social activities. The elderly who have a fear of falling are also likely to lack the self-confidence needed to manage and prevent falls, which in turn results in repeat falls. Fear of falling is a significant risk factor related to falls, as it is related to anxiety, distress, limited physical function, a rising risk of falls, and a decreased quality of life (10). The elderly people who had experienced falls are also a burden on their family, community and affect the overall economic loss to society. The elderly people who fall, lose confidence in their daily activities or have a fear of falling that in turn 
affects their ability to work resulting in reduced social responsibility and inevitably leads to more falls (11).

\section{Methodology}

This was a cross sectional survey conducted in a rural community in Nakornnayok province in the eastern part of Thailand. A total 100 elderly people aged between 6074 years were included in this study. The inclusion criteria were age, no problems with movement experience of falling at least once in the past 12 months, and receipt of permission from their doctors to participate in this research project. Physical testing: consisted of gait and balance performance by time up and go test (TUGT) and one-legged stance test (OLST). TUGT is a simple test used to evaluate elderly people's ability to walk. OLST is a gold standard assessment tool that evaluates elderly people's balance ability and monitors functional balance over time. The Falls Efficacy Scale (FES) (12) measured the fear of falling and assesses the degree of perceived self-efficacy in avoiding a fall during routine activity. There is a 10 -item scale measuring confidence in one's ability to avoid falling during the performance of activities of daily living (ADL). WHOQoL - BREF is a set of questionnaire used globally to assess quality of life. There are 26 items in the WHOQoL - BREF instrument. This set of questionnaires is divided in four domains: physical (domain 1), psychological (domain 2), social (domain 3 ), and environmental (domain 4). The physical domains include: activity of daily live; dependence on medicinal substances and medical aids; energy and fatigue; mobility, pain and discomfort; sleep and rest; work capacity. The psychological domain includes: bodily image and appearance; negative and positive feelings; self-esteem spirituality / religion / personal beliefs; thinking, learning, memory and concentration. Social relationships consist of: personal relationships; social support; sexual activity. The environment domain refers to: financial resources; freedom, physical safety and security. Health and social care include: accessibility and quality; home environment; opportunities for acquiring new information and skills; participation in and opportunities for recreation / leisure activities; physical environment (pollution / noise / traffic / climate); transport. The completed questionnaires were coded and the data were analyzed using the SPSS statistical package version 16 (SPSS Inc., Chicago, IL, USA). Descriptive statistics, including frequency distribution, percentage, mean, and SD, were used to describe the following demographic and socioeconomic characteristics data, gait and balance performance, fear of falling, and quality of life amongst the elderly. This study was approved by the Ethics Review Committee for Research Involving Human Research Subjects, Health Sciences Group of Chulalongkorn University (COA No.326/58). Prior to participating in the study, the study objectives and data collection procedures were fully explained to the participants who then signed a written informed consent form to indicate their willingness to participate in the study.

\section{Results}

The general characteristics of the participants are shown in Table 1. A convenient sample of 100 elderly people who had at least one fall in the previous year were selected for this study. More than half $(58 \%)$ were female. Participants ranged in age from 61 to 74 years with a mean age of $66.1(\mathrm{SD}=3.79)$. Most participants reported that their marital status was as a couple (e.g., married, common law partnership $66.7 \%$ ). The majority of the participants indicated their educational level was primary education (1-6 academic years; $61 \%$ ) followed by high school level (19\%); a few participants had a Bachelor's degree (8\%). Nearly $70 \%$ were not employed (housewives/retirees). Most of them (57\%) had a history of falls 1 time in the previous year. The time of previous falling was during the day time between $8.00 \mathrm{am}-3.00$ $\mathrm{pm}(38 \%)$. More than half of them $(58 \%)$ had fallen outside their homes. Sixty-eight percent reported that their cause of falling were intrinsic factors (impair balance and slip).

Table 1: Demographic characteristic of study participants

\begin{tabular}{|l|l|l|l|}
\hline \multicolumn{2}{|l|}{ Variables } & $\mathrm{n}=100$ & $\%$ \\
\hline Demographic characteristics & & \\
\hline & Age 61-74 years: age range 71-74 years & 51 & 51 \\
\hline & Female & 58 & 58 \\
\hline & Elementary education & 61 & 61 \\
\hline & Agriculture & 33 & 33 \\
\hline & Living on 1 ${ }^{\text {st }}$ floor & 60 & 60 \\
\hline & Cause of last fall: Impaired balance & 68 & 68 \\
\hline & Place of last fall: Around the home & 58 & 58 \\
\hline & Time of Day of Last Fall : 8.00 am -3.00 pm & 38 & 38 \\
\hline & History of falls in 12 months & & \\
\hline & 1 fall & 57 & 57 \\
\hline 2 falls & 41 & 41 \\
\hline & 3 falls & 2 & 2 \\
\hline
\end{tabular}

Risk factor of falls

Gait, balance and fear of falling

The TUGT and OLST were used to assess the risk of falling. The average time of the TUGT test from this study was over 10 seconds $(29 \%>10$ seconds, $71 \%>14$ seconds). For OLST, the mean was 9.29 seconds. Mean results of fear of falling was 48.96 . More than $20 \%$ of the participants increased their risk of falling and $10 \%$ of the participant had a fear of falling.

\section{Table 2: Mean and SD of TUGT and OLST}

\begin{tabular}{|l|l|l|l|l|l|}
\hline Variables & Min & Max & Mean & S.D. \\
\hline & TUG test & 10 & 24 & 15.7 & 3.25 \\
\hline & OLST & 4 & 22 & 9.2 & 3.70 \\
\hline
\end{tabular}




\section{Table 3 Fear of falling among participants}

\begin{tabular}{|l|l|l|l|l}
\hline & Activity: & $\begin{array}{l}\text { No } \\
\text { confidence } \\
\%\end{array}$ & $\begin{array}{l}\text { Confidence } \\
\%\end{array}$ & $\begin{array}{l}\text { Fully } \\
\text { assured } \\
\%\end{array}$ \\
\hline 1 & Getting dressed and undressed & 32 & 30 & 38 \\
\hline 2 & $\begin{array}{l}\text { Preparation of meals not requiring carrying } \\
\text { heavy or hot objects }\end{array}$ & 20 & 29 & 51 \\
\hline 3 & Take a bath or shower & 42 & 43 & 15 \\
\hline 4 & Get in and out of a chair & 12 & 29 & 59 \\
\hline 5 & Get in and out of bed & 36 & 41 & 23 \\
\hline 6 & Reach for the door or telephone & 51 & 36 & 13 \\
\hline 7 & Walk around the house & 6 & 12 & 82 \\
\hline 8 & Pick object from a high shelf & 29 & 41 & 30 \\
\hline 9 & Household work & 13 & 64 & 23 \\
\hline 10 & Walk to buy something & 31 & 37 & 32 \\
\hline Min-Max 10-100 & \multicolumn{2}{l}{} \\
\hline \multicolumn{2}{|l}{ Mean (SD) 48.96 (26.46) } &
\end{tabular}

Table 4 Quality of Life among respondents

\begin{tabular}{|c|c|c|c|}
\hline & Mean(SD) & Min-Max & Level \\
\hline \multicolumn{4}{|l|}{ Quality of life } \\
\hline \begin{tabular}{l|l} 
Physical health \\
\end{tabular} & $21.66(2.27)$ & $17-28$ & Moderate \\
\hline Psychological health & $18.86(2.49)$ & $13-23$ & Moderate \\
\hline Social relationships & $9.11(1.82)$ & $5-14$ & Moderate \\
\hline \begin{tabular}{|l|} 
Environment \\
\end{tabular} & $25.04(3.27)$ & $17-35$ & Moderate \\
\hline Total Quality of life & $80.43(7.98)$ & $62-103$ & Moderate \\
\hline
\end{tabular}

\section{Discussion}

The aim of this study was to explore gait and balance performance, fear of falling, and quality of life among elderly people. The results presented the majority of the participants as female, with an average age of 66 , and a history of falls at least once in the previous year, who had fallen outside their homes, with the cause of the fall being intrinsic factors (impaired balance and slipping) which were similar to the study (7) reported that nearly half of their participants also reported at least one fall in the previous year. Gait and balance were assessed by TUGT and OLST. A previous study found that the TUGT score in the elderly people between fallers and nonfallers were different: the elderly people who fell had higher TUG scores (slower) than those who did not (13). Moreover, they mentioned that the TUG was able to better predict fall outcome than other clinical measures. Results from one study reported slower gait speed, shorter stride length and increased step width in the fear of falling group of participants (14). The findings of this study showed $20 \%$ of the participants increased their risk of falling from a fear of falling score (80). Half of the participants were not confident in the activity of reaching for the door or telephone and when taking a bath or shower. Recent study also revealed that the participants' lives were limited by a fear of falling and a need to give up activities such as working in the garden or traveling. Moreover, the researcher explained that fear of falling was a negative experience, directly connected to fall effect such as pain, body injury, lack of confidence, and disability (15). Fear of falling can lead to a decline in overall quality of life and increase the risk of falls through a decrease in physical activity. According to the World Health Organization (WHO), Quality of Life is defined as individual's perception about their life in the perspective of their culture, value, expectations, and concerns. It is based on many factors like personal physical health, psychological health, and social relationship and environment. The participants with a history of falls in this study had a moderate score in their quality of life. Similarly, the study (16) revealed that almost all of the participants with fall history had a good quality of life and, had a better perception of their quality of life. This could be explained as the participants' perception that their life is good. Similarly, their perceptions related to their health was good. A study that focused on the African-American elderly also reported that subjective health status is associated with fall and fall-efficacy (17).

\section{Conclusion}

This study described elderly people's risk factors through physical testing, falls risk factors, and quality of life. Overall, the elderly people in this study were at risk of falls, but their qualities of life were at a moderate level. Quality of life was significantly related with the risk of fall. It can be concluded that providing support to enhance the quality of life of the elderly might be a good falls prevention strategy.

\section{Reference}

1. Bird M.L, Pittaway J.K, Cuisick I., Rattrary M., Ahuja K. D. K. Age-Related Changes in Physical Fall Risk Factors: Results from a 3 Year Followup of Community Dwelling Older Adults in Tasmania, Australia. Int. Journal Environment Public Health. 2013;10, 5989-5997.

2. Donoghue et al. Effects of fear of falling and activity restriction on normal and dual task walking in community dwelling older adults. Gait \& Posture Journal. 2013;38:120-124.

3. Gates S, Fisher JD, Cooke MW, Carter YH, Lamb SE. Multifactorial assessment and targeted intervention for preventing falls and injuries among older people in community and emergency care settings: systematic review and meta-analysis. BMJ 2008;336:130-3.

4. World Health Organization 2012.

5. Paramattakan A. Prevent Falls in Elderly. 5th Center of Health Nakornratchaseema , Department of Health, Ministry of Public Health.Ministry of Public Health. (2016).

6. Bekibele C.O., \& Gureje O. Fall Incidence in a Population of Elderly Persons in Nigeria. Gerontology Journal. 2010; 56:278-283.

7. Rapp K. Fall incidence in Germany: results of two population-based studies, and comparison of retrospective and prospective falls data collection methods. BMC Geriatrics 2014, 14:105.

8. Silvia D, Ersilia L, Francesca B, Roberto F, Carlo La V, \& Eva N. Risk Factors for Falls in Community-dwelling Older People: A Systematic Review and Meta-analysis. Epidemiology Journal. 2010; 21(5). 
9. Tiedmann A, Fairhall N, Close CT, \& Lord SR. Exercise to prevent falls in older adults: an update meta-analysis and best practice recommendations. NSW Public Health Bulletin. 2011;22(3-4):78-83.

10. O'Halloran, A.M., Penard, N. , Galli, A., Fan, C.W., Robertson, I.H., \& Kenny, R.A. Falls and falls efficacy: the role of sustained attention in older adults. 2011; 19;11:85.

11. Taguchi C.K., Teixeira J.P., Alves L.V., Oliveira P.F., Raposo O.F. Quality of Life and Gait in Elderly Group. Int Arch Otorhinolaryngol Journal. 2016;20:235-240.

12. Tinetti, M.E., Richman, D., \& Powell, L. Falls efficacy as a measure of fear of falling. Journal of Gerontology. 1999 45(6): 239-243.

13. Bhatt. Dynamic Gait Stability, Clinical Correlates, and Prognosis of Falls Among Community-Dwelling Older Adults. Arch Phys Med Rehabil . 2011;92.

14. Dingova M., Kralova E. Fear of falling among community dwelling older adults. Central European Journal of Nursing and Midwifery Journal.;8(1): 580-587.

15. Deandrea S., Lucenteforte E., Bravi F., Foschi R., La V.C., \& Negri E. Risk factors for falls in community-dwelling older people: a systematic review and meta-analysis. Epidemiology Journal. 2010; 21(5):658-68.

16. Hartholt KA, van Beeck EF, Polinder S, van der Velde N, van Lieshout EM, Panneman MJ, van der Cammen TJ, Patka P. Societal consequences of falls in the older population: injuries, healthcare costs, and long-term reduced quality of life. J Trauma. 2011;71:748753.

17. Tiernan C., Lysack C., Neufeld S., Goldberg A., Lichtenberg P.A. (2014). Falls efficacy and selfrated health in older African American adults. Arch Gerontol Geriatr Journal. 2014; 58(1): 8894. 